\title{
Bone Healing and Hormonal Bioassay in Patients with Long-Bone Fractures and Concomitant Head Injury
}

\author{
Fathy G. Khallaf $^{a} \quad$ Elijah O. Kehinde ${ }^{b}$ Sundus Hussein ${ }^{c}$ \\ ${ }^{a}$ Department of Orthopaedic Surgery, Jahra Hospital, Kuwait, ${ }^{b}$ Department of Surgery, Faculty of Medicine, Kuwait \\ University, and ${ }^{\mathrm{C} D e p a r t m e n t}$ of Pathology, Mubarak Al-Kabeer Hospital, Jabriya, Kuwait
}

\section{Key Words}

Long-bone fractures · Brain injury · Fracture healing ·

Hormonal bioassay

\begin{abstract}
Objective: The aim of this study is to investigate healing of fractures in patients with concomitant head injuries and to measure blood hormone levels to elucidate the mechanism of a possible accelerated osteogenesis. Materials and Methods: One hundred and sixty-two patients were included in this study and divided into 3 cohorts: group $A$ with head injuries only $(n=52)$; group $B$ with head injuries as well as longbone fractures $(n=50)$; group $C$ with long-bone fractures only $(n=60)$. Fracture-healing parameters including time of appearance and thickness of the bridging callus, and blood hormonal assays were measured and compared using Student's t test. Results: The mean time to healing was significantly lower in cohort B $(6.9 \pm 2.9$ weeks) than C ( $22.4 \pm 8.7$ weeks; $p=0.001)$. The mean thickness of the healing callus was significantly higher in cohort B $(26.3 \pm 9.7 \mathrm{~mm})$ than $C$ $(8.1 \pm 5.9 \mathrm{~mm} ; \mathrm{p}=0.002)$. The mean healing rate was also higher in cohort $B(4.5 \pm 2.3 \mathrm{~mm} /$ week $)$ than $C(0.38 \pm 0.21$ $\mathrm{mm} /$ week; $p=0.001$ ). Blood hormonal assays in group $B$ showed higher values of parathyroid hormone and growth
\end{abstract}

\begin{tabular}{ll}
\hline KARGER & $\begin{array}{l}\text { ( } 2016 \text { S. Karger AG, Basel } \\
1011-7571 / 16 / 0254-0336 \$ 39.50 / 0\end{array}$ \\
E-Mail karger@karger.com & $\begin{array}{l}\text { This is an Open Access article licensed under the terms of the } \\
\text { www.karger.com/mpp }\end{array}$ \\
$\begin{array}{l}\text { Creative Commons Attribution-NonCommercial 3.0 Un- } \\
\text { ported license (CC BY-NC) (www.karger.com/OA-license), } \\
\text { applicable to the online version of the article only. Distribu- } \\
\text { tion permitted for non-commercial purposes only. }\end{array}$
\end{tabular}

hormone than in group C. However, adrenaline and noradrenaline values were lower in group $B$ than in group $C$ at all measured time intervals, and correspondingly leptin was lower in all groups $(p=0.001)$. Corticosteroid values were normal in group $B$ compared to slightly higher values in group C, also at all measured time intervals. Conclusion: In this study, healing of fractures in patients with concomitant head injuries was accelerated, thereby indicating an involvement of a combined neurohormonal mechanism.

(C) 2016 S. Karger AG, Basel

\section{Introduction}

The increased rate of fracture healing and abundant callus formation of long-bone fractures in patients with concomitant acute post-traumatic head injury and the frequent occurrence of heterotopic ossification are wellknown orthopedic observations [1-6]. In spite of numerous attempts to establish the mechanisms involved whereby severe head injury influences osteogenesis at a distant site, the relation remains poorly understood. Some studies have shown that the cause of these clinical observations could be due to either circulating humoral factors, which are released in the damaged brain, or through di- 
rect nerve signaling pathways $[7,8]$. Neurohormonal or neurohumoral mechanisms were also suggested in other studies $[9,10]$. Therefore, the aim of this study was to investigate fracture-healing parameters and the role of hormones in acute traumatic head injuries, in trauma patients with or without long-bone fractures.

\section{Subjects and Methods}

One hundred and sixty-two patients were included in this study. Inclusion criteria were patients being within the age group of 20-60 years, and without a history of chronic ill health or systemic diseases. Exclusion criteria were patients being on permanent medications and undergoing therapy for diabetes mellitus, ischemic heart diseases, chronic renal failure, endocrine diseases, and corticosteroid treatment for bronchial asthma, rheumatoid arthritis, other arthritides, and inflammatory and autoimmune diseases.

From September 19, 2011, to October 1, 2013, patients were included in the study in 3 groups: group A comprised patients with severe head injury [defined as patients admitted to the intensive care unit with a Glasgow Coma Scale (GCS) score of 8 or less] without long-bone fractures; group B were patients with severe head injury and long-bone diaphyseal fractures (humerus, femur, and tibia), and group C consisted of patients with long-bone fractures only.

The participants recruited into each group were as follows: group A, 52 (males: 49 and females: 3); group B, 50 (males: 48 and females: 2), and group C, 60 (males: 55 and females: 5). The characteristics of the injuries including GCS, cause of injury, type of fracture and status of the participants are listed in table 1. The GCS for groups A and B ranged from 3 to 8 , and road traffic accidents were the major causes of the injury in the groups (A: $36, \mathrm{~B}: 45, \mathrm{C}$ : 38). Head injuries were involved in groups $A$ and $B$. Types of fracture in groups $\mathrm{A}-\mathrm{C}$ included the humerus, femur, and tibia.

The computed tomographic (CT) data at presentation are listed in table 2 for groups A and B. The most important CT data for groups A and B were skull fractures in 33 versus 24, cranial bones only in 24 versus 18 , subdural hematoma in 30 versus 16, subarachnoid hemorrhage in 28 versus 13, diffuse brain edema in 23 versus 32 , and lobe and intracerebral hemorrhage contusion in 22 versus 24. All fractures of a long-bone in group $\mathrm{C}$ were managed surgically and skeletally stabilized using plates or intramedullary nails.

Healing parameters of long-bone fractures in groups $\mathrm{B}$ and $\mathrm{C}$ were calculated. It included time to union in weeks, maximal thickness of the union-bridging callus as measured in the CT scan, and healing rate, which was defined as the maximal thickness of the union-bridging callus in millimeters divided by the time to healing in weeks.

Blood samples were withdrawn from the injured patients of all groups at: (a) $24 \mathrm{~h}$, (b) $72 \mathrm{~h}$, (c) 1 week, (d) 2 weeks, and (e) 3 weeks from the time of injury. A $10-\mathrm{ml}$ blood aliquot was withdrawn each time. These blood samples were processed by centrifugation and after separation of red blood cells; separated sera were preserved at $-85^{\circ} \mathrm{C}$.

The blood samples from different patient groups were used to measure the level of parathyroid hormone, growth hormone, cor-
Table 1. Patient biodata and characteristics of injuries

\begin{tabular}{|c|c|c|c|}
\hline & Group A & Group B & Group C \\
\hline Number recruited & 52 & 50 & 60 \\
\hline \multicolumn{4}{|l|}{ Age, years } \\
\hline Mean & $32 \pm 5.7$ & $31.4 \pm 8.5$ & $33 \pm 7.8$ \\
\hline Range & $20-60$ & $21-59$ & $20-60$ \\
\hline $\operatorname{Sex}(M / F)$ & $49 / 3$ & $48 / 2$ & $55 / 5$ \\
\hline \multicolumn{4}{|l|}{ GCS score } \\
\hline Mean & 6 & 7 & 15 \\
\hline Range & $3-8$ & $3-8$ & 0 \\
\hline \multicolumn{4}{|l|}{ Cause of injury } \\
\hline RTA & 36 & 45 & 38 \\
\hline Fallen object & 5 & 2 & 0 \\
\hline Fall from height & 5 & 3 & 5 \\
\hline Blast & 1 & 0 & 1 \\
\hline Industrial trauma & 5 & 0 & 12 \\
\hline Head injury & yes & yes & 0 \\
\hline \multicolumn{4}{|l|}{ Types of fracture } \\
\hline Humerus & 0 & 18 & 17 \\
\hline Femur & 0 & 21 & 22 \\
\hline Tibia or fibula & 0 & 19 & 30 \\
\hline Status of patient (alive/dead) & $52 / 7$ & $50 / 1$ & $60 / 0$ \\
\hline
\end{tabular}

Group A: patients with severe head injury only; group B: patients with severe head injury and long-bone diaphyseal fractures; group C: patients with long-bone fractures only. RTA = Road traffic accident.

Table 2. Findings of brain CT scan in groups A and B

\begin{tabular}{|c|c|c|c|c|}
\hline \multirow[t]{2}{*}{ CT scan head findings } & \multicolumn{2}{|c|}{ Group A } & \multicolumn{2}{|c|}{ Group B } \\
\hline & $\mathrm{n}$ & $\%$ & $\mathrm{n}$ & $\%$ \\
\hline Skull fractures & 33 & 63.5 & 24 & 48 \\
\hline Cranial bones only & 24 & 46.2 & 18 & 36 \\
\hline Facial bones only & 4 & 7.7 & 4 & 8 \\
\hline Cranial and facial fractures & 5 & 9.6 & 2 & 4 \\
\hline Fractured base of the skull & 3 & 5.7 & & \\
\hline Subdural hematoma & 30 & 57.7 & 16 & 32 \\
\hline Subarachnoid hemorrhage & 28 & 53.8 & 13 & 26 \\
\hline Diffuse brain edema & 23 & 44.2 & 32 & 64 \\
\hline \multicolumn{5}{|l|}{ Lobe and intracerebral } \\
\hline hemorrhagic contusion & 22 & 42.3 & 24 & 48 \\
\hline Midline shift & 12 & 23.1 & 3 & 6 \\
\hline Extradural hematoma & 10 & 19.2 & 15 & 30 \\
\hline Pneumocephalus & 6 & 11.5 & 9 & 18 \\
\hline Impending conization & 6 & 11.5 & 2 & 4 \\
\hline Diffuse axonal brain injury & 5 & 9.6 & 3 & 6 \\
\hline Intraventricular hemorrhage & 4 & 7.7 & 2 & 4 \\
\hline
\end{tabular}

Group A: patients with severe head injury only; group B: patients with severe head injury and long-bone diaphyseal fractures. 
Table 3. Comparison of healing indicators of long-bone fractures in patients of groups B and C

\begin{tabular}{|c|c|c|c|c|c|c|}
\hline $\begin{array}{l}\text { Patient } \\
\text { group }\end{array}$ & $\begin{array}{l}\text { Patients } \\
\text { who finished } \\
\text { follow-up }\end{array}$ & $\begin{array}{l}\text { Long-bone } \\
\text { fractures }\end{array}$ & $\begin{array}{l}\text { Fractures } \\
\text { without union }\end{array}$ & $\begin{array}{l}\text { Mean } \\
\text { healing } \\
\text { time, weeks }\end{array}$ & $\begin{array}{l}\text { Mean } \\
\text { maximal thickness } \\
\text { of union callus, mm }\end{array}$ & $\begin{array}{l}\text { Mean } \\
\text { healing rate, } \\
\mathrm{mm} / \text { week }\end{array}$ \\
\hline $\mathrm{C}$ & 60 & 69 & $9(13 \%)$ & $22.4^{1,2}(13-41)$ & $8.1^{3,4}(2-20)$ & $0.38^{5,6}(0.11-1)$ \\
\hline
\end{tabular}

${ }^{1} \mathrm{p}=0.001,{ }^{2} \mathrm{p}=0.01,{ }^{3} \mathrm{p}=0.0001,{ }^{4} \mathrm{p}=0.001,{ }^{5} \mathrm{p}=0.001,{ }^{6} \mathrm{p}=0.001$. Group B: patients with severe head injury and long-bone diaphyseal fractures; group C: patients with long-bone fractures only. Figures in parentheses are ranges unless indicated otherwise.

ticosteroids, adrenaline, noradrenaline, and leptin. Parathyroid hormone, serum growth hormone, and corticosteroids were assayed using an Immulite Automated Immunoassay Analyzer, which is a continuous, random access instrument and performs automated chemiluminescent immunoassays. The remaining hormones were assayed in serum using the enzyme-linked immunosorbent assay technique.

\section{Statistical Analysis}

The demographic and the clinical data of bone healing and hormonal assays were analyzed using SPSS for Windows (version 16). Means and standard deviations were determined. Mean scores between any two groups of patients were compared using the $\chi^{2}$ square and the Student $t$ test. A p value $<0.05$ was considered statistically significant.

\section{Results}

The mean age of the patients matched evenly in the 3 groups of the study, as shown in table 3. The long-bone fractures in head injury patients (group B) showed statistically significant shortened times to appearance of a unionbridging callus in the follow-up X-rays compared to the times of union of fractures in patients with long-bone fractures only (group $\mathrm{C} ; \mathrm{p}=0.001$ ). In addition, long-bone fractures showed a statistically significant higher thickness of the union-bridging callus and the healing rate in $\mathrm{B}$ patients compared to $C$ patients $(\mathrm{p}=0.002$ and $\mathrm{p}=0.001$, respectively), as shown in table 3 and figure 1.

Head injury without or with long-bone fractures in groups A and B resulted in statistically significant higher values of parathyroid hormone compared to patients with long-bone fractures only (group C) and to normal levels in the healthy subjects $(\mathrm{p} 1=0.03$, paired t test between groups $\mathrm{A}$ and $\mathrm{C} ; \mathrm{p} 2=0.01$, between group $\mathrm{A}$ and normal average in healthy subjects; p3 $=0.04$, between groups $\mathrm{B}$ and $\mathrm{C} ; \mathrm{p} 4=0.03$, between group $\mathrm{B}$ and normal range in healthy subjects). Patients with head injury com-

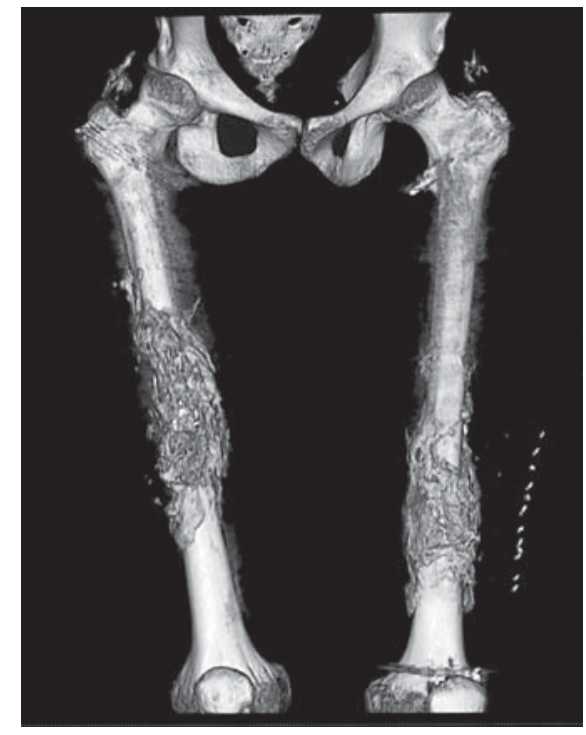

Fig. 1. Three-dimensional CT scan of both femora with accelerated fracture healing and abundant callus formation 6 weeks after injury in a group B patient with severe head injury.

bined with long-bone fractures (group B) had higher levels of parathyroid hormone compared with patients with head injury and no long-bone fractures (group A; p5 = 0.04). In all groups of patients, the parathyroid hormone fell to subnormal levels below the normal levels in healthy subjects from the end of the second week to the end of the third week ( $\mathrm{p} 2=0.01, \mathrm{p} 4=0.01$, and $\mathrm{p} 5=0.03$ between group $\mathrm{C}$ and normal subjects); the parathyroid hormone levels in all groups are shown in table 4 and figure 2.

Growth hormone was statistically significantly higher in patients of all groups compared to healthy subjects ( $\mathrm{p} 2=0.001, \mathrm{p} 4=0.001$, and $\mathrm{p} 5=0.002$, paired $\mathrm{t}$ test $)$. It fell to subnormal levels at the end of the third week in patients of group C only, as shown in table 4 . 
Table 4. Values of the hormonal assay in the study groups $\mathrm{A}-\mathrm{C}$ and in normal subjects from $24 \mathrm{~h}$ to 3 weeks after injury

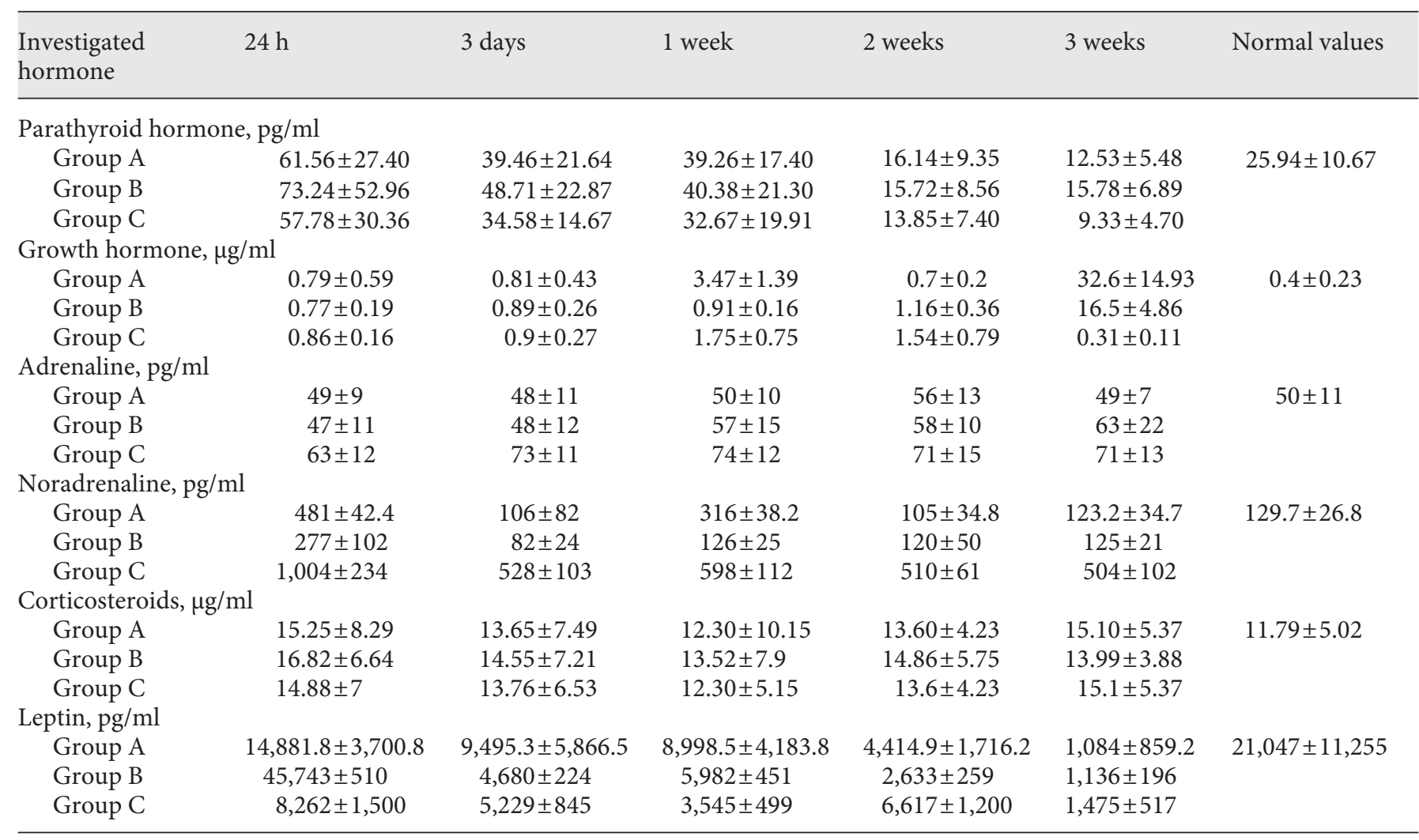

Fig. 2. Line chart of serum parathyroid hormone values in patient groups $\mathrm{A}-\mathrm{C}$ during their first 3 weeks of follow-up, with D indicating the normal level in healthy subjects.

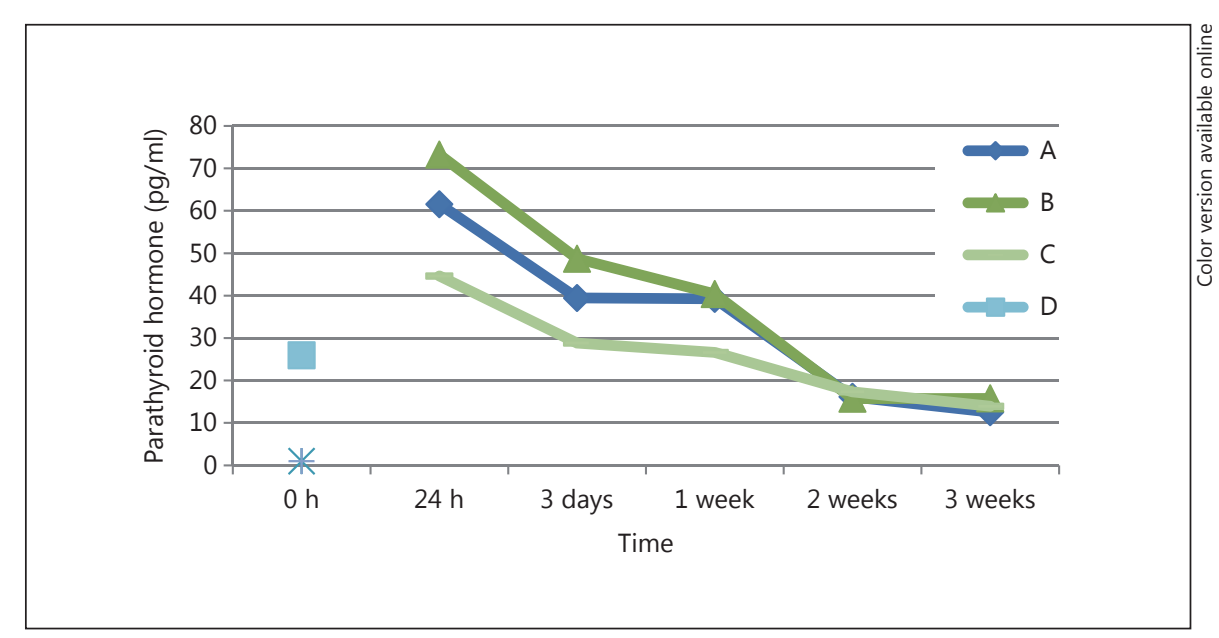

All patient groups showed normal levels of corticosteroids compared to healthy subjects, without statistically significant differences between the patients in the different groups and during the whole 3-week period of followup. The levels were normal in group B compared to the slightly higher values in group $\mathrm{C}$, and the normal levels in healthy subjects, but without statistical significance, as shown in table 4.

Patients with long-bone fractures only showed consistent and statistically significant higher values of noradren- 
Fig. 3. Column chart of serum noradrenaline values in patient groups $\mathrm{A}-\mathrm{C}$ during their first 3 weeks of follow-up, with D indicating the normal level in healthy subjects.

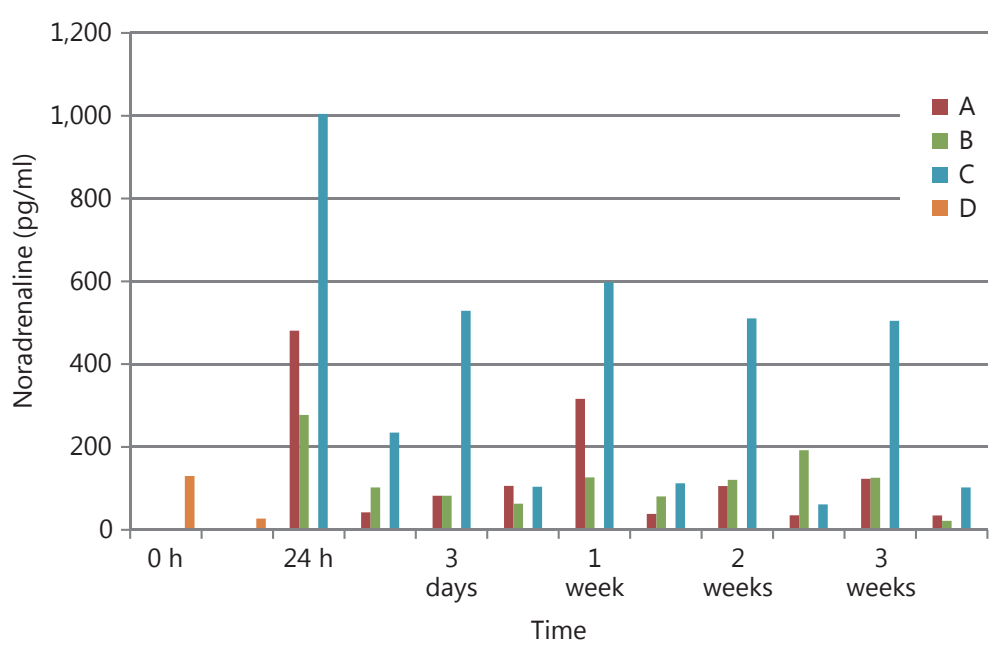

aline compared to patients with head injury alone or associated with long-bone fractures, and to the normal range in healthy subjects $(\mathrm{p} 1=0.001, \mathrm{p} 3=0.001$, and $\mathrm{p} 5=0.001$, paired $t$ test). The levels of noradrenaline in patients with head injury with or without long-bone fractures were comparable to the hormone levels in healthy subjects during the 3 weeks of follow-up, without any statistically significant difference, as shown in table 4 and figure 3.

The adrenaline showed the same pattern as noradrenaline with a statistically significant higher level of adrenaline in patients with long-bone fractures only compared to patients with head injury with or without long-bone fractures and normal levels $(\mathrm{p} 1=0.001, \mathrm{p} 3=0.001$, and $\mathrm{p} 5=0.002$, paired $\mathrm{t}$ test). Again, the levels of adrenaline in patients with head injury with or without long-bone fractures were normal or subnormal during the 3 weeks of follow-up, with a statistically insignificant difference, as shown in table 4.

The assessment of leptin showed a statistically significant decrease during the 3 weeks of follow-up in blood samples of all groups of patients compared to normal levels $(\mathrm{p} 1=0.002, \mathrm{p} 3=0.001$, and $\mathrm{p} 5=0.001$, paired t test), as shown in table 4 .

\section{Discussion}

In this prospective controlled study, the findings that the healing of long-bone fractures was faster and had a more exuberant and florid formation of the union callus in patients with associated severe head injury compared to patients with long-bone fractures only confirmed those of previous studies $[1,8,9]$.

Based on the hormonal bioassay of blood samples from patients recruited in this study, the consistent and statistically significant higher levels of parathyroid hormone and growth hormone could indicate the hormonal or neurohormonal mechanism of the accelerated healing of long-bone fractures in patients with associated severe head injury.

The statistically significant higher level of noradrenaline and adrenaline in patients with long-bone fractures might only reflect a relative inhibition of nerve signaling of the sympathetic nervous system via neuromediators (mainly the principal inhibitory neurotransmitter $\gamma$-aminobutyric acid and possibly other neurotrophins or neuropeptides) in the hypothalamus in head injury patients with or without long-bone fractures. This in turn could lead to substantial mobilization of undifferentiated mesenchymal stem cells and osteoprogenitor cells to the peripheral circulation to induce accelerated abundant healing of long-bone fractures, indicating a combined neurohormonal mechanism to explain this accelerated healing [10-14].

The normal level of corticosteroids in severe head injury patients with associated long-bone fractures could reflect a relative neuronal inhibition of the suprarenal cortex in producing the antiosteogenic corticosteroids, inducing an inflammatory condition, which is mandatory to bone healing. 
The statistically significant low blood level of leptin in patients with severe head injury and associated long bone fractures and in patients of the other groups might confirm its antiosteogenic effect due to its downregulation in the environment of accelerated osteogenesis. Karsenty [14] characterized the mechanism by which leptin regulates bone mass, showed that the sympathetic nervous system is the intermediate between leptin and osteoblasts, and therefore suggested that $\beta$-blockers, drugs which are used routinely to treat high blood pressure, could also help reverse osteoporosis.

Our suggested mechanism of accelerated bone healing in head injury patients with associated long-bone fractures confirmed the findings of previous studies [15-23] where released growth factors, basically bone morphogenetic protein, in brain-injured patients were in relation to increased bone healing, and where it was suggested that trauma to the central nervous system could increase the release of, or decreased uptake of, bone formation mediators that might enter the systemic circulation. Other chemicals might be released from the brain, which act to stimulate the local production of bone morphogenetic protein or other growth factors or mediators.

The traditional view is that bone healing and remodeling are regulated by autocrine/paracrine and hormonal mechanisms; recent work suggests an influence of higher integrating neuronal pathways, and the most striking evidence for this nervous system control is the leptin-hypothalamus inhibitory effect on the body bone mass. Several neuropeptides, neurotrophins, and classical neurotransmitters, such as noradrenaline and serotonin, were described as possible neuromediators [10-14].

In their study of the anatomical analysis of the innervation of murine femora and the effects of denervation of these femora on the cellularity of the femoral bone marrow and the mobilization of the osteoprogenitor stem cells into peripheral blood, Afan et al. [10] concluded that the nervous system has an important role in the selective control of bone marrow cellularity, and that the denervation leads to a decrease in the femoral bone marrow cellularity and mobilization of progenitor cells to the peripheral blood. The study also indicates a possible nervous control of cell proliferation within the bone marrow. These studies confirm our results, and their conclusions support our proposed possible mechanism to explain the acceleration of bone healing in head injury patients.

The major strength of this study is its contribution to the understanding of the regulatory mechanism of bone healing, and that bone healing might be controlled neuronally and centrally via the hypothalamus-sympathetic nervous system pathway, through neuromediators of neurotransmitters, neuropeptides, or neurotrophins. Accordingly, we suggest that sympatholytic medications such as $\beta$-blockers and others may enhance bone healing and may have a therapeutic impact on the treatment of delayed fracture union and nonunion, but this should remain a topic for further experimental research work.

The limitations of our study include: (a) the determination of the exact time of union, whether clinical or radiological, and the controversies of definition of radiological union, which may need daily X-rays, which is impossible for very obvious reasons; (b) the dependence basically on the bridging callus as radiological criterion among others to assess union; (c) the recruitment of patients with different long-bone fractures (humeral, femoral, and tibial) which have different healing potentials and rates.

\section{Conclusion}

The current study demonstrated that long-bone fractures in patients with concomitant head injuries healed at a faster rate, and with more exuberant and florid callus formation, and suggested a combined neurohormonal mechanism with a central neuronal control by a relative inhibition of the sympathetic nervous system as a possible cause for such an accelerated healing.

\section{Acknowledgment}

This project was sponsored by the Kuwait Foundation for Advancement of Sciences, grant No. 2010/1302/04.

\section{Disclosure Statement}

There is no conflict of interest.
References
Newman RJ, Stone MH, Mukherjee SK: Ac- celerated fracture union in association with severe head injury. Injury 1987;18:241-246.
2 Perkins R, Skirving AP: Callus formation and the rate of healing of femoral fractures in pa- tients with head injuries. J Bone Joint Surg (Br) 1987;69:521-524.
-3 Malisano LP, Stevens D, Hunter GA: The management of long bone fractures in the head-injured polytrauma patients. J Orthop Trauma 1994;8:1-5. 
4 Sevitt S: Bone Repair and Fracture Healing in Man. New York, Churchill Livingstone, 1981, pp 231-243.

5 Apley AG, Solomon L: Apley's System of Orthopedics and Fractures, ed 6. London, Butterworth, 1982, pp 333-368.

6 Rockwood CA, Green DP: Rockwood and Green's Fractures in Adults, ed 6. Philadelphia, Lippincott, 2006, chapt 8: Bone and joint healing, pp 297-312.

7 Morley J, Marsh S, Drakoulakis E, et al: Does traumatic brain injury result in accelerated fracture healing? Injury 2005;36:363-368.

$\checkmark 8$ Giannoudis PV, Mushtaq S, Harwood P, et al: Accelerated bone healing and excessive callus formation in patients with femoral fracture and head injury. Injury 2006;37S:S18-S24.

9 Yang TY, Wang TC, Tsai YH, et al: The effects of an injury to the brain on bone healing and callus formation in young adults with fractures of the femoral shaft. J Bone Joint Surg (Br) 2012;94:227-230.

10 Afan AM, Broome CS, Nicholls SE, et al: Bone marrow innervation regulates cellular retention in the murine hemopoietic system. $\mathrm{Br} \mathrm{J}$ Haematol 1997;98:569-577.
11 Kang S, Bennet CN, Gerin I, et al: Wnt signaling stimulates osteoblastogenesis of mesenchymal precursors by suppressing CCAAT/ enhance-binding protein $\alpha$ and peroxisome proliferator-activated receptors. J Biol Chem 2007;282:14515-14524.

12 Sherman BE, Chole RA: Sympathectomy which induces membranous bone remodeling has no effect on endochondral long bone remodeling in vivo. J Bone Miner Res 2000; 15:1354-1360.

13 Ducy P, Amling M, Takeda S: Leptin inhibits bone formation through a hypothalamic relay: a central control of bone mass. Cell 2000; 100:197-207.

14 Karsenty G: The central regulation of bone remodeling. Trends Endocrinol Metab 2000;11: 437-439.

15 Bidner SM, Rubins IM, Desjardins JV, et al: Evidence for a humoral mechanism for enhanced osteogenesis after head injury. J Bone Joint Surg (Am) 1990;72:1144-1149.

16 Gautschi OP, Joesbury K, Meagher J, et al: Serum mediated osteogenic effect of traumatic brain injured patients. J Am Coll Surg 2006; 203:S37.
7 Cadosch D, Gautschi OP, Thyer M, et al: Humoral factors enhance fracture-healing and callus formation in patients with traumatic brain injury. J Bone Joint Surg (Am) 2009;91: 282-288.

18 Raju K: The effect of head injury on fracture healing. J Orthop 2007;4:e7.

19 Beeton CA, Brooks RA, Chatfield D, et al: Circulating levels of insulin-like growth factor-1 and insulin-like growth factor binding protein-3 in patients with severe head injury. J Bone Joint Surg (Br) 2002;84:434-439.

20 Reddi AH: Bone morphogenetic proteins: from basic science to clinical applications. J Bone Joint Surg (Am) 2001;83(suppl 1):S1-S6.

21 Tsuji K, Bandyopadhyay A, Harfe BD, et al: BMP2 activity, although dispensable for bone formation, is required for the initiation of fracture healing. Nat Genet 2006;38:1424-1429.

22 Baldock PA, Sanisbury A, Couzens M, et al: Hypothalamic Y2 receptors regulate bone formation. J Clin Invest 2002;109:915-921.

23 Kondo H, Tsuji K, Kitahara K, et al: Unloading-induced bone loss occurs through the central control via sympathetic system. J Bone Miner Res 2003;18(suppl 2):S45. 